\title{
Regulatory Requirements for Integrated Management of Agro-Food Chain Activities: Advantages and Disadvantages
}

\author{
Chief Assist. Prof. Antoaneta Stoyanova, PhD \\ University of Economics - Varna, Bulgaria \\ a.stoyanova@ue-varna.bg
}

\begin{abstract}
Market dynamics of goods stems from ensuring conformity to requirements related to the introduction of various regulations and rules for their implementation. By imposing new regulatory requirements to various sectors of production and trade and bringing existing requirements up to date, it is possible to guarantee consumer health of a particular sector of consumption throughout the whole chain. The purpose of the present paper is to analyse advantages and disadvantages in applying an integrated approach to the implementation of uniform regulatory rules which are to ensure the quality and safety of goods across the entire agro-food chain. By applying the principles of the preventive approach to legislation, we seek to emphasize the key role of governmental agencies and their activities in setting common priority policies aimed at public health protection. The usefulness of the systematic approach in developing the general legislative framework which regulates safety along the entire agro-food chain has been also assessed. The results of said analysis show that the regulatory requirements are directly related to the strategic issues and goals of public administration and control regarding the provision and consumption of safe foods that will guarantee public health.
\end{abstract}

Keywords: agro-food chain, regulations/legislature, quality, safety, foodstuffs, consumers

JEL Code: $Q 010$

DOI: https://doi.org/10.36997/IJUSV-ESS/2020.9.1.54

\section{Introduction}

Modern concepts and regulatory requirements on food safety emerged in the middle of the last century as a result of rapid development of technology and a continual rise in the range and types of foods on offer, growing consumer expectations and signed agreements for free and open trade related to cross border food distribution in various geographical regions (Peri, 2006).

Ensuring consumption of foods which are not harmful to consumers' health has become an issue of crucial importance worldwide. This issue can be tackled by dealing with a number of technological, economic, legislative and organizational problems which call for new regulatory requirements that are based on sound scientific principles. This prerequisite serves to bring together the efforts of many a state and international institutions aiming to harmonize regulations toward a successful outcome. The presence of similar risks to consumer health can be attributed to the influence of certain objective factors on human safety. These circumstances call for an international response and are seen as the basis for a revision of existing legislative criteria, already in place. (Orriss \& Whitehead, 2000).

The actions of the state and departmental institutions which are bound by the legislative framework seek to improve measures of control in plant growing and animal breeding, their processing into food and protection of public health. Subsequent steps to restructure legislation involve actions aimed at improving safety policies and strategies and ensuring control over all participants in the food to agro-food chain. (Dimitrova, 2020).

\section{Thesis statement and literature review}

The dynamics of the market and free trade of goods are linked to the unification and harmonization of state and departmental requirements towards a single legislative framework. The binding of requirements is seen as a responsible step in the implementation of new approaches which are set in the food safety policies (Garengo \& Biazzo, 2012).

The legislation in the area of food or the Food Law covers all rules governing the stages of production, processing and distribution of food. Additionally, rules aiming to guarantee fair trade 
practices and protection of consumer interests and their right to be informed, are discussed in the articles of Regulation (EO) № 178/2002 (Parliament European, 2002).

The quality and safety of goods on the market is largely dependent on the quality of raw materials, production materials and finished products which will guarantee quantifiable results in accordance with quality criteria. Achieving compliance of goods with regulatory requirements is a necessary prerequisite for achieving sustainable consumption. (Ivanova, Vassileva, Stefanov, Tipova, 2012)

European legislation on food safety first appeared in 1964 when the generally valid directives (Directive 64/433/EEC and Directive 64/432/EEC) were adopted. Legislation was further developed in Council Directive 85/374/EE (Council Directive 92/59/EEC) regulating the manufacture and supply of safe and high-quality foods (Parliament European, 1992). The change in legislature adopted in 2004, which became known as the Hygiene Package covers the implementation of the EU policy to develop a comprehensive legislative basis for (the safety and hygiene of plants, animals, food and feed on the basis of theoretically well-grounded opinions and monitoring, which will help to evaluate the suitability and effectiveness of these legislative rules). Its scope ranges from primary production to consumption and destruction of food. The principles set in the legislation of 2004 aim to preserve people's health through adequate selection of methods and tools for monitoring and control, aiming to guarantee compliance with adopted requirements (European Parliament, 1992).

The adopted legislative changes result in a shift in the status of responsibility by transferring responsibility regarding food quality and food safety from the particular government institutions to food manufacturers and food retailers themselves. Food industry operators face the need to plan measures and prove they have achieved compliance with standards and regulatory requirements (Orriss \& Whitehead, 2000; Boutrif, 2003). Consequently, global harmonization of requirements is a key step to the world population sharing the same degree of protection against foodborne hazards. Owing to the adopted regulatory framework, consumers today are able to make a more informed choice (Boisrobert, Stjepanovic, Oh, \& Lelieveld, 2009).

Therefore, the quality and safety of food that is offered, lies within the responsibility of the producer and the control applied, which aim to ensure compliance with all the requirements for the respective industry sector.

In many cases, a given segment in the food chain will produce goods that will serve as raw materials for the production of other goods and thus, the elements of the chain interact with each other to be linked in a continuous process. The imposition of regulatory requirements for each of the elements in the food chain with specific rules for a given product can be seen as a deterrent that makes it difficult to implement or use them in another element of the chain when these are to be included in another production. In addition, the application of certain rules in the form of requirements may subsequently hinder the application of the integrated approach for control, thus posing problems in the traceability of goods, which in turn may compromise safety.

It is known that the current regulatory requirements lack coordination and interconnectedness especially with regards to the legislative framework and its unified approach to establishing communication when it is necessary to communicate newly arisen plant and animal diseases and food contaminants. The principle in use so far has it that each competent body can exert control only in the area related to the site and scope of control, identified by the relevant regulation Act (for example, the lack of commitment in official control of food and feed and also when new information on health hazards for people and animals or GMOs is presented, incl. plant protection products and environmental risks (Stoyanova, 2020).

This situation clearly demonstrates the absence of a unified and systematic approach in handling common threats which are interrelated and dependent on the individual links in the food chain. Deficiencies in the regulatory basis also make it difficult to reach the necessary level of protection in accordance with adopted safety policies. 
The purpose of the present paper is to look into the positive and negative sides in applying a unified approach and the effect of introducing updated regulatory rules, when food safety throughout the entire agro-food chain is to be ensured.

The need to implement a more harmonized and coherent approach to monitoring and execution of measures which ensure compliance with the legislative framework throughout the entire agro-food chain, makes it necessary to restructure, update and modify the approach formerly adopted in 2004 legislation.

The search for binding solutions and uniform requirements require that all aspects of the activities of operators throughout the food chain be covered and integrated, which was made possible with the adoption of EU Regulation 2017/625 in 2017. The legal framework integrates the whole business of the food chain, identifying each of its elements as a complete and continual process, by introducing a policy and linking activities to the type and frequency of controls according to the rules established by the regulation (European Parliament, 2017).

The restructuring, rationalization and amendment of the rules related to the control of all participants, from production to consumption and destruction of goods are combined into one whole (Wu et al. 2014). This large-scale and integrated approach, in which the responsibilities of food and feed producers and the competent authorities are clearly cut and interdependent, represents a comprehensive, effective and dynamic change in the food policy (Żurek, 2011).

The correct application of these rules, hereinafter referred to as "collective Union legislation in the field of the agricultural and food chain", contributes to the successful functioning of the internal (local) market.

\section{Methodology of legislative framework of the agro-food chain}

The main method applied in the present study is the qualitative approach which involves analyzing the positive and negative sides of the approach and the structure and scope of changes in the legislative requirements. The usefulness of a systematic approach in developing the general legislative framework, which is to ensure safety across the agro-food chain, has been also assessed.

The preventive approach has been evaluated, particularly its usefulness in defining the concept set in the legislation which serves as the basis to lay down food safety requirements along the entire agro-food chain. Received data from the analysis show that regulatory requirements are directly related to the strategic issues and goals of state governing where public health is concerned.

The importance of the general principles set in the requirements for animal welfare and their role in mitigating hazards for plant and human health has been particularly emphasized, alongside improvement of food quality and safety measures in providing food for the population of each country. In addition to being influenced by the goals and strategies at the corporate level, the strategy of the legislation is directly influenced by strategic decisions in the functional areas of each of the scope of the agro-food chain.

The inclusion of the preventive approach in the EU legislation presents the very basis for mutual commitment to responsibilities and a necessary condition for a quick response to emergencies along the entire food chain. In this way, each EU member state will be able to share responsibility at different levels - production, institutional or governmental. In the Republic of Bulgaria, the EU legislation on agro-food chain has been brought into effect with the adoption of a national regulatory Act - the Law on Management of the Agro-food Chain (ZAHV, 2020). For the first time in our country, the law on the agro-food chain was adopted as a single law, which would unite all the activities in the agro-food chain.

Until now, each of the elements of the agro-food chain has been governed by a separate law which determines the framework and the scope of control only for the subject treated by the law e.g. Food Act, Veterinary Medicine Act, Animal Husbandry Act, GMO Act, Environmental Protection Act, Beekeeping Act, in other words, laws that are specific in their requirements for control of various elements of the food chain. 
Within the meaning of the law, the "Agro-food chain" is treated as encompassing all the stages of production, processing and distribution of food and feed according to Art. 3 (16) of Regulation (EC) 178/2002, as well as the production and distribution of plant and animal reproductive material, taking into account all aspects that have a potential impact on food and feed safety and are seen as a continuous process (Regulation (EO) 178/2002).

\section{Results and discussion}

The focus of European and national legislation is placed on revising and supplementing the accepted general principles in the field of raw materials and ready-to-eat foods that reach consumers. Other principles are also included such as the principle of precaution and the principle of protection of consumer interests in order to upgrade the already established rules to harmonized rules for production and trade practices.

Recently introduced amendments in the legislation are justified by the necessity to supplement and restructure existing rules and adopt new ones. The aim is to establish common rules for official controls in the EU in order to ensure the correct application and enforcement of legislation in the scope of the agro-food chain for the protection of human health, animal health and welfare and plant health which is to be observed by every EU member state.

The organizational - methodological approach which is set in the new legislative framework for food safety management of the agro - food chain provides the very basis for a clearly structured system of requirements and control rules on safety management. Said harmonized rules which reflect the positive aspects of applied practices in each segment of the food chain help to take informed decisions when prevention of public health in relation to food consumption is at stake. By applying approaches in the legislation, which are based on preventive and validated requirements, it becomes possible to harmonize the latest requirements to the business operators, participating in the agro-food chain.

It is our belief that combining these requirements is a fairly effective and appropriate means as there are many similarities and likeness between them. With the development of common legislative rules which aim to guarantee the safety of the food offered and consumed, certain benefits could be achieved as follows:

- Prerequisites for cooperation between EU countries are created by clarifying and improving the rules on cooperation and administrative assistance between state control institutions in EU countries. EU states guarantee exchange of information among their national agencies and other law-enforcing departments and court instances regarding possible cases of non-compliance by building integrated computer systems to manage information on official control.

- The approval and implementation of joint actions are based on individual planning and control of the activity for the given sector or region and are aimed at influencing the general risks affecting human health, plant and animal health at national or regional level. Setting and implementation of common specifications for conducting official control across EU member states implies that control procedures will ensure the required level of protection against hazards as provided for in the EU legislation in the area of agro-food chain (Andreeva, Dimitrova, 2020).

- $\quad$ Uniform requirements in the newly introduced EU legislation require planning and implementation of joint actions in agricultural and food safety related to the impact of identified threats in the food chain worldwide.

- The application of common requirements across the entire agro-food chain and collaboration among the competent authorities of the Member States, through exchange of information is directly dependent on cutting down additional costs for inspection, withdrawal and disposal of food by each department when food accidents are registered.

- Cost cutting is important when there are mechanisms to improve the vertical and horizontal communication at all levels of state control bodies responsible for applying control. This 
is a necessary prerequisite for preventing the occurrence of food fraud and unfair trade practices and taking coordinate action against such irregularities, both at national level and within the EU.

- The new legislative framework helps to fund initiatives for amendment of regulations which in terms of technological and scientific advancement are to become more effective in their implementation. In the event of emergency measures, opportunities will be created for Union co-financing upon the entry into force of plant health legislation which is to regulate cases for compensation of producers/farmers for loss of value in relation to plant material that is subject to destruction.

- $\quad$ Fixing the size of mandatory fees for all registered food and feed enterprises and operators in the sectors of plant growing and plant reproductive material allows the costs of control to be distributed throughout the agro-food chain. This step will allow the competent authorities to cover, through fees, the costs incurred for them in carrying out their official control obligations throughout the chain and in certain related areas.

- The uniform requirements laid down in the legislation will provide reliable evidence showing that all interrelated activities down the agro-food chain are carried out in an objective and transparent way. Adoption of the new legislative framework along the entire chain shall ensure that all criteria for safety of manufactured raw materials, convenience food and readymade products have been covered in full.

- $\quad$ The requirements associated with state control and that of departmental agencies help to periodically evaluate the effectiveness of measures put into practice, thus guaranteeing expected results. Taking into account the presence of uniform requirements and the change in the level of control for individual elements of the agro-food chain (such as crop production, which has not been covered with the same depth so far), we can say that the adopted normative rules related to their introduction will contribute to the implementation of the efficiency principle.

- The adopted requirements of the general legislative framework allow the identification and tracking of activities across the entire agro-food chain. The rules for systematic tracking and identification of batches of extracted raw materials and their monitoring throughout the whole production cycle, including stages of sale and consumption, is one of the most important steps in ensuring public health.

Monitoring of the achieved effect from the implementation of the planned and coordinated control measures is done at both state level and cross-border movement of goods from third countries.

- The mechanisms for cooperation among national control authorities on matters of cross-border infringements of EU rules are being improved. Where necessary, non-compliances may be prosecuted not only in the Member State in which the infringement was detected but also in the Member State in which it occurred.

- $\quad$ Even though this approach allows for timely actions to be taken to counteract some serious irregularities along the entire agro-food chain, it may also serve the purpose of building effective cooperation among competent authorities.

- Quantifying the effect of the applied control measures helps to generate data and exchange information among the participants in the process of production, trade and consumption of food in a single network within the EU. This is the basis for confirming or supplementing the adopted policies using objective data.

The derived positives create conditions for coordinated communication and an opportunity for building lasting relationships between diverse but interdependent and connected state institutions. They can be seen as a basis for achieving the goals of sustainable development. The emphasis is on the key role of the control of individual government agencies as factors that interact and set priority policies aimed at protecting public health through the production and consumption of safe food. 
Based on the analysis of the introduced general legislative requirements across the agro-food chain, some major weaknesses can be identified as follows:

- The first shortcoming stems from the fact that no guidelines and rules have been developed on how the mechanisms for interaction and coordination between the competent authorities will be implemented in practice, both at national level and among the competent authorities such as the European Commission and the competent authorities of other Member States.

- The second shortcoming is the insufficient number of staff and lack of resources (human and financial resources to be allotted to individual state institutions) needed for the implementation of the legal framework in achieving compliance. Each individual state agency is directly involved in the food chain control and needs sufficient competent and qualified staff to ensure continuity and consistency in their work towards achieving the implementation objectives.

- $\quad$ Provision of efficient and effective formal checks and control and other official activities related to the safety and health of humans, animals and plants and protection of the environment depend entirely on the knowledge and competence acquired on all matters associated with the proper implementation of EU law. It is important to define the need for periodic appropriate training to encourage the implementation of the adopted unified approach to official control and other related activities which so far have been left out of the scope of control.

- The third shortcoming seen in the management of costs incurred by measures for official control is related to the financial framework, which is also supported by the amount of fees set by law. As early as 2011, an external study found that the financing of official controls through fees falls short of the goal to provide an adequate level of resources for the conduct of official controls (EK, 2013). Fees do not allow competent authorities to fully cover for the costs incurred, so their revenue depends on national budgetary policies, and not always are these equally distributed among the different control agencies. Some of the sectoral institutions are likely to experience shortage of resources, owing to redirection of funds to competing priorities.

- A fourth drawback lies in the various degree of equality and fairness which can be explained by the fact that the methods used to calculate fees and the list of costs covered by individual Member States appear to vary among operators from different Member States. This inconsistency also arises from the management and distribution of costs, which is currently different for the different control agencies. Therefore steps need to be taken to harmonize these fees in accordance with the multiannual financial framework however taking into account the existing legal bases.

- The fifth shortcoming is associated with the competence of staff who execute control. Their scope of competence needs to be further extended following an increase in their work load which entails additional responsibilities and powers. In the restructured regulatory requirements for control laid down in legal documents, it is written that competent control authorities can delegate part of their duties to other parties bound by the scope of the legal framework across the agro-food chain. It is equally important to say that the legislation does not specify how these actions should be carried out in practice and under what conditions so as to ensure impartial, consistent and quality official controls, including other official activities as well. It is important to note that the requirements stipulate that the body to which powers are delegated must, in particular, be accredited in accordance with the International Organization for Standardization (ISO) for conducting inspections (Regulation 2017/625).

- $\quad$ The sixth shortcoming addresses the impossibility to apply unified rules under specific conditions for control along the agro-food chain. This shortcoming can be explained with the fact that these uniform rules are complemented by other rules specific to official controls and are in line with the needs in these specific areas. The adoption of specific rules, as well as the binding and consolidation of control among the various competent authorities would make it difficult to apply these special measures in view of the bulk of unified requirements at hand. 
The answers to these questions boil down to what specific measures need to be taken in cases of identified irregularities or non-compliance. The specific responsibilities arising from these additional rules in relation to the rules generally applicable in each Member State are unlikely to ensure the same effectiveness of official controls.

- The strictly individual characteristics featured in the properties of the goods may be a reason for discrepancies in the methods and techniques for the application of universal control and thus can be identified as the seventh drawback. Uniform rules are not normally valid when there are specific requirements to consider, in terms of quality and safety of goods along the agro-food chain. This is the basis for determining the scope and manner of control, including equipment at hand and instrumental methods for assessing the quality and safety of specific goods.

- And lastly, the eight shortcoming is seen when there is evidence of non-compliance with Union legislation in the field of the agro-food chain which may require enforcement action to be taken in more than one member state in the EU. In this case, there might arise apprehensions and doubts about whether the consistency in the control of goods in the course of their processing and sale is being ensured.

The above shortcomings can be used as the stepping stone to look for such mechanisms which will make all set requirements for control feasible. The hererin identified shortcomings are a key factor to ensure that the activities for guidance and control for all participants are effective, taking into account the minimum allowable exceptions related to product safety.

Actions taken for control in compliance with existing regulations can be used in support of planned decisions which may subsequently be assessed for the degree of their impact on the activities of the individual segments in the agro-food chain, in order to manage it as one whole.

The herein presented advantages and disadvantages of the legislative framework for control over the agro-food chain are associated with many activities, which are the basis for building and implementing a unified management approach, through which an adequate response to the imposed regulatory requirements can be given.

Applying the principles of safety management, the legislative framework focuses mainly on prevention, placing an emphasis on the pre-planned measures to control interconnected activities in the food chain. This task can be accomplished in conjunction with the development of measures and planning of objectives to ensure desired unity between food producers and suppliers throughout the food chain. In this way, all participants have the opportunity to work responsibly and provide food that meets the requirements to consumers.

The results of the analysis give us reasons to argue that in unifying the scope of control and overlapping the activities related to control of each unit of the agro-food chain, it becomes necessary to implement mechanisms for strategic and tactical management. This is made possible through the optimization and allocation of materials and financial resources to organizations.

In this way, the internal structure of each of the participants in the control of the agro-food chain is improved and the interactions among participants are also improved in the long run. Otherwise, the identified discrepancies will deepen, and the established practice of managing control activities will increasingly move away from the growing requirements.

Providing control in various hotspots and monitoring all stages, from the receipt of raw materials, through the production process and on to the consumption of the finished product, virtually gives all interconnected government agencies the opportunity to actually correct rather than respond to health incidents.

\section{Conclusion}

In view of the above, we can draw the conclusion that the changes in the legal framework related to the application of approaches for interaction and scientific knowledge, aim to strengthen the existing framework in order to guarantee food safety among all participants in the process. 
Being aware of the place and role of existing and newly-established governmental structures, it becomes clear that the food operators themselves, agencies for inspection and control, departmental units and non-governmental organizations (NGOs) can be seen as some of the key factors which influence the analysis, evaluation and impact on safety across the entire food chain. The effectiveness of actions taken to address cases of non-compliance that are being proportionate to the impact on food safety requirements is continuously assessed.

The application of a single legislative approach to official controls across the entire food chain is essential for achieving prevention and establishing communication among individual actors to guarantee safety of goods.

The legislative framework of the agro-food chain, which encompasses relevant international safety requirements, provides conditions for identification and assessment of the degree of compliance with said requirements, which to various degree influence directly or indirectly the health of consumers.

In this way, market conditions are being created which will allow only safe products to reach the end user. Thus, the state takes upon itself the responsibility to look after the health of each of its citizens by passing appropriate legislative initiatives and regulations that will ensure safety of food products.

\section{References}

1. Boisrobert, C., Stjepanovic, A., Oh, S., \& Lelieveld, H. (2009). Ensuring global food safety: Exploring global harmonization (1st ed.). New York: Academic Press.

2. Boutrif, E. (2003). The new role of Codex Alimentarius in the context of WTO/SPS agreement. Food Control, 14(2), 81-88.

3. Garengo, P., \& Biazzo, S. (2012) From ISO quality standards to an integrated management system: an implementation process in SME. Total Quality Management \& Business Excellence, 24(3-4), 310-335.

4. Ivanova D., Vassileva E., Stefanov S., N. Tipova (2012) The Role of Stakeholders in Establishing Sustainable Consumption in Bulgaria. Special issue of "Economics Scientific Book of Poznań University” (“ZESZYTY NAUKOWE”). Witczak, Poznan, 2011, No 216, pp. 26 - 33

5. Orriss, G., \& Whitehead, A. (2000). Hazard analysis and critical control point (HACCP) as a part of an overall quality assurance system in international food trade. Food control, 11(5), pp. 345-351.

6. Parliament European. (1964, 1992) Council Directive 85/374/EEC and Council Directive 92/59/EEC on General Product Safety, 01.1964, 29.06.1992.

7. Parliament, European. (2002) Regulation (EC) No 178/2002 of the European Parliament and of the Council laying down the general principles and requirements of food law, establishing the European Food Safety Authority and laying down procedures in matters of food safety. OJ L 31, 1.2.2002, p. 1-24

8. Parliament European. (2017) Regulation (EU) 2017/625 of the European Parliament and of the Council of 15 March 2017 on official controls and other official activities performed to ensure the application of food and feed law, rules on animal health and welfare, plant health and plant. OJ L 95, 7.4.2017, p. 1-142.

9. Peri, C. (2006) The universe of food quality. Food quality and preference. 17(1-2), pp. 3-8.

10. Stefanova, M. (2015) Possibilities for Integrating the Requirements of Food Quality and Safety Management Standards. Scientific works of University of Food technologies 2016, Plovdiv: University of Food technologies, 63, (1), 111 - 118.

11. Stoyanova, A. (2020) Unified Approach to Integrated Food Quality and Safety Management. Sustainable Supply Chain Management for the Global Economy: Handbook of Research, Hershey, Pennsylvania, USA: IGI Global Publ., pp. 238 - 259. 
12. Żurek, K. (2011). European food regulation after enlargement: facing the challenges of diversity. Martinus Nijhoff Publishers.

13. Wu, F., Groopman, J. D., \& Pestka, J. J. (2014). Public health impacts of foodborne mycotoxins. Annual Review of Food Science and Technology, 5, p. 351-372

14. Andreeva, A., Dimitrova, D. (2020) Nova pravna ramka za administrativno satrudnichestvo mejdu darjavite chelnki na ES za povishavane na zastitata na potrebitelite. Product quality and certification: Proceedings of an international Scientific-practical conference dedicated to the 100th anniversary of the University of Economics - Varna, Varna: Science and Economics, pp 46-55

15. Dimitrowa, D. (2020) Spesifiki na administrativno-pravnata zastita na potrebitelite. Product quality and certification: Proceedings of an international Scientific-practical conference dedicated to the 100th anniversary of the University of Economics - Varna, Science and Economics, pp. 56-64

16. Evropeiska komisiya (2013) Communication from the commission to the council and the european parliament Healthier animals and plants and a safer agri-food chain Modernized legal framework for a more competitive EU.

Available from: https://ec.europa.eu/transparency/regdoc/rep/1/2013/BG/1-2013-264-BG-F11.Pdf [Accessed 06/05/2013].

17. Zakon za upravlenie na agrohranitelnata veriga. (2020), DV. Br.51 ot 05.06.2020. 